\title{
Cutaneous Melanoma pT2 TNM Finding v8
}

National Cancer Institute

\section{Source}

National Cancer Institute. Cutaneous Melanoma pT2 TNM Finding v8. NCI Thesaurus. Code C136944.

Cutaneous melanoma measuring more than 1.0 and equal to or less than $2.0 \mathrm{~mm}$ in thickness. Ulceration status: Unknown or unspecified. (from AJCC 8th Ed.) 